\title{
Professionalism and Ethics of Accounting in Financial Reporting: An Overview of Nigerian Scenerio
}

\author{
Bushi Kasimu Musa, (MSc /MBA) \\ Independent Researcher and Consultant
}

Doi:10.19044/esj.2019.v15n25p224 URL:http://dx.doi.org/10.19044/esj.2019.v15n25p224

\begin{abstract}
This paper focuses on evaluating the concept of professionalism and ethics of accounting standards on the quality of financial reports in Nigeria. To achieve this objective, data was collected from primary and secondary sources. Questionnaires were distributed with the use of simple random sampling technique in selecting a sample size of 75, consisting of accountant and auditors and relevant data obtained. Accounting ethics was measured with professional independence and professional competence, while financial reporting quality was measured using the qualitative attribute of dependability and understandability. Ordinary Least Square was utilised to develop a theoretical equation model to test the formulated hypotheses. Understandability was significant at 5\% level in associating with both competence and independence respectively. Reliability was found to be significant at 5\% level, only with independence. On the basis of these findings, therefore, it was recommended that corporate bodies should establish ethics compliance department to enhance the enforcement of ethical compliance in the various economy institutions.
\end{abstract}

Keywords: Professional Independence Ethics, Accounting Ethics, Financial Report

\section{Introduction}

There has been growing concern in recent times that the recent wave of corporate scandals, which are associated with ethical bankruptcy in the accountancy practice, is eroding the relevance of accounting and financial reporting quality. The various corporate collapses have led to increased scrutiny of deficiencies in the financial reporting process and corporate disclosure requirements of corporate organizations. This has had a negative and cumulative impact on the perceived credibility of financial reporting. This concern is now at the front position of public debate about the accounting profession and its effectiveness (IFAC, 2003). It should be noted that the core 
of accounting profession in every organization is ethics. The quality of financial reporting points to a limit in which the financial reports of an entity, its economic status, and functions, which are measured over period of time, are presented honestly (Talebnia, Salehi \& Jabbarzade, 2011). Steering and Working Committees on Accounting (2004), which examined how public confidence in financial reporting can be restored, noted that accounting and auditing systems, and policy in the management process, requires a set of best practices for governance and financial reporting. The extent to which financial reporting is perceived to be true and trusted depends on far more than the actions and decisions of individuals or sophisticated "mechanisms" for the whole system (Enderle, 2006). This is because business practices, environments, and culture are known to possess the capability, in varying degrees, to affect the value of the financial reporting systems and, hence, its confidence (Gilligan, 1977; Langenderfer \& Rockness, 1990; Paradice \& Dejoie, 1991). Therefore, reliability of, and trust in the financial reporting system cannot be an issue of either personal or institutional ethics alone (Brenkert, 2004).

\section{Statement of Problem}

Ethics in professional accounting are of utmost importance. However, the widespread corruption in the society and the failure of organization in every parts of the world have once more increased the need for accounting professionals to adhere strictly to the codes of professional ethics prescribe by international accounting bodies. According to Ogbonna and Appeah (2011), the widespread corruption in the business environment seems to be the order of the day in all societies. Recently, business ethics have attracted renewed attention globally due to the several notorious corporate scandals like those of Enron, WorldCom, Arthur Anderson, Tyco International, Adelphia, Cadbury PLC, Lever Brothers PLC amongst others (Ojeka, Ogundana \& Iyoha, 2017). Unfortunately, these collapses have led to a widespread disregard for the reputation of the accounting profession. Additionally, the growing importance of government regulations, the amplified scrutiny of media, and the increasing pressure from different stakeholders have placed the business ethics challenge on the strategic agenda of virtually all firms (Weaver, Trevino \& Cochran, 1999). The ethical lapses among public accountants have necessitated a revision of the accounting professional standards (Rist, 2002). Interestingly, professional accountant working in accounting firms are faced with new challenges within the profession as a result of the debacles of large corporations(Swift,2002).

Organizational cultures and environment pose a good opportunity for accountants to exploit the loopholes in reporting and financial management. expected to foster the growth of ethical education and awareness, they are 
often faced with stiff resistance from the top level management (Fisher\& Lovell, 2009).

Accountants have obligations to shareholders, creditors, employees, suppliers, the government, the accounting profession, and the general public at large Therefore, behaving ethically is an essential and expected trait. In this regard, an accountant bears the consequences of his moral choices not only based on his own life but also the lives of other people. The nature of the work carried out by accountants and auditors require a high level of ethics. Furthermore, shareholders, potential shareholders, and other users of the financial statement rely heavily on their professional competence.

\section{Objectives of the Study}

The main objective of the study is to critically examine the effect of accounting ethics on the quality of financial reports of Nigerian organizations. The specific objectives are:

Although finance and accounting departments in most organizations are To evaluate the professionalism and ethics of accounting in Nigeria;

- To examine the effect of disclosure on the quality of financial reports in Nigeria;

- To examine the effect of objectivity on the quality of financial reports in Nigeria;

- To examine the effect of integrity on the quality of financial reports in Nigeria;

- To assess the effect of competence on the quality of financial reports in Nigeria.

\section{Formulation of the Hypotheses}

$\mathrm{H}_{01}$ : Professional independence of accountants and auditors does not have significant effect on the understandability of their financial reports.

$\mathrm{H}_{02}$ : Professional competence of accountants does not have significant effect on the understandability of their financial statements

$\mathrm{H}_{03}$ : Professional independence of accountants does not have significant effect on the reliability of their financial reports

$\mathrm{H}_{04}$ : Professional competence of accountants does not have significant effect on the reliability of their financial reports

\section{Literature Review}

\section{Ethics}

Fisher (2004) highlighted the concept of an individual's personal belief about what is right or wrong, good or bad. It is the arbiter of an individual's evaluation of the "rightness" or otherwise of his or her actions. Miner (2002) defined ethics as right or wrong actions that stems from the value and 
expectation of society. Mintz and Morris (2007) notes that ethics are acceptable standards of behavior that define how people ought to act (i.e., prescriptive), and not how people really act (i.e., descriptive).

Nevertheless, the generic sociological meaning of the concept of ethics seems to provide a common ground for most of them. Sociologically speaking, ethics are provided in order to render behavior intelligible and to "prevent conflicts from arising by bridging the gap between action and expectation" (Scott \& Lyman, 1968). Though it is often regarded as subjective, it is traceable to the foundation of an individual's belief system and judged within its context. On the other hand, Logsdon and Yuthas (1997) noted that the ethical stance of a firm is constructed based on the expectation of society. In essence, this refers to the legitimate claims made by the constituencies to whom the firm interacts. According to Hanekom (1984), the question of ethics is one that is linked with the history of mankind. Ethics deals with the character, conduct, and morals of human beings. It deals with good or bad, right or wrong behaviour. It evaluates conduct against some absolute criteria and puts negative or positive values on it. It is the reflective study of what one ought to do, or how one ought to live. Cole (2002) conceptualized that ethics is a set of moral principles or values used by organization to steer the conduct of the organization itself and its employees in all their business activities, both internal and external, and in relation to the outside world. Ethics is interpreted to be a certain culture of society that includes a specific form of values while in the scholarship researching. Thus, it is an ideology from social context or codes of conduct. The interpretation of the meaning associated with ethics varies greatly from society to society.

Ethical problems are a very relevant issue present in many aspects of real life. These situations can be examined through several branches and under several grids of analysis, modern or classic (Filipe et al., 2011). A squishing mark of the accounting profession is its acceptance of the responsibility to act in the public interest (IFAC, 2005). Key qualities which appear in the codes of ethics of professional bodies include independence, integrity, objectivity, competence, and judgment. For example, the ICAEW's introduction to its 'Guide to professional Ethics' (ICAEW, 1997) includes a list of five fundamental principles which either expressly mentions or clearly implies all of these qualities, along with other related qualities such as honesty, fairdealing, truthfulness, courtesy, skill and diligence (Growthorpe, 2005).

\section{Professional Ethics}

According to International Federation of Accountants (2006) in its code of ethics for professional accountants, a distinguishing mark of the accountancy profession is its acceptance of the responsibility to act in the public interest. This code establishes the fundamental principles of 
professional ethics for professional accountants and provides a conceptual framework for applying those principles. The conceptual framework provides guidance on fundamental ethical principles. Professional accountants are required to apply this conceptual framework to identify threats to compliance with the fundamental principles to evaluate their significance and, if such threats are other than clearly insignificant, to apply safeguards to eliminate them or reduce them to an acceptable level. This is done such that compliance with the fundamental principles is not compromised.

Professional accountant is required to comply with the following fundamental principles:

\section{i) Integrity}

The principle of integrity imposes an obligation on all Chartered Accountants to be straightforward and honest in professional and business relationships. Integrity also implies fair dealing and truthfulness.

\section{ii) Objectivity}

A professional accountant should not allow bias, conflict of interest, or undue influence of others to override professional or business judgments. The principle of objectivity imposes an obligation on Chartered Accountants to be fair, intellectually honest, and free of conflicts of interest. Regardless of service or capacity, Chartered Accountants should protect the integrity of their professional services and maintain objectivity in their judgment. According to Izedonmi (2012), the principle of objectivity imposes a serious obligation on all accountants whether in private practice or industry to avoid jobs, assignments, relationships, and situations that are capable of compromising their professional judgment due to either coercion, undue influence from people, conflict of interest or even bias.

\section{iii) Independence}

Independence is an attitude of mind characterized by integrity and objectivity in approach to audit assignment. Arowoshegbe, Uniamikogbo and Atu (2017) stated that auditor's independence means that when performing his statutory duties, an auditor considers the interest of third parties, most of whom are unknown to him who will be placing reliance on the accuracy of financial statements prepared by him, to be of paramount importance. According to the Institute of Chartered Accountants of Nigeria (ICAN) (2009), Independence of an Auditor is of two types:

1.Independence of Mind: The state of mind that permits the expression of a conclusion without being affected by influences that 
compromise professional judgment, allowing an individual to act with integrity, and exercise objectivity and professional skepticism.

3. Independence in Appearance: The avoidance of facts and circumstances are so significant such that a reasonable and informed third party, having knowledge of all relevant information, including safeguards applied, would reasonably conclude that a firm or a member of the assurance team's integrity, objectivity, or professional skepticism had been compromised. As opined by Izedonmi (2012), independence is a very crucial issue in enhancing the auditor's objectivity in his findings and opinions expressed in financial statements. Therefore, not only must the auditor be independent in fact and in attitude of mind, he must also be considered to be independent.

4.

\section{iv) Professional Competence and Due Care}

A professional accountant has a continuous duty of maintaining professional knowledge and skill at the level required to ensure that a client or employer receives competent professional service based on current developments in practice, legislation, and techniques. A professional accountant should act diligently and in accordance with applicable technical and professional standards when providing professional services.

\section{v) Confidentiality}

A professional accountant should respect the confidentiality of information acquired as a result of professional and business relationships and should not disclose any such information to third parties without proper and specific authority unless there is a legal or professional right or duty to disclose. Confidential information acquired as a result of professional and business relationships should not be used for the personal advantage of the professional accountant or third parties. Nevertheless, it is not always possible to conduct evaluations without identifying information, such as names. ICAN (2009) stated that the principle of confidentiality imposes an obligation on Chartered Accountants to refrain from disclosing to persons outside the firm, or within the firm or employing organization, confidential information acquired as a result of professional and business relationships without proper and specific authority unless there is a legal or professional right or duty to disclose such.

\section{vi) Professional Behavior}

A professional accountant should comply with relevant laws and regulations and should avoid any action that discredits the profession. The code specifically stated that professional accountants should take qualitative 
and quantitative factors into account when considering the significance of a threat. If the professional accountant cannot implement appropriate safeguards, the professional accountant should decline or discontinue the specific professional service involved or where necessary resign from the client (in the case of a professional accountant in public practice) or the employing organization (in the case of a professional accountant in business). If a professional accountant inadvertently violate a provision of this code, such an inadvertent violation, depending on the nature and significance of the matter, may not compromise compliance with the fundamental principles provided. Once the violation is discovered, the violation is corrected promptly and any necessary safeguards are applied.

\section{vii) Conformity to Technical Standard}

According to Atu (2009), audit work should be done with due professional skill, care, and caution in conformity with approved auditing standards and statutory provisions and other regulatory and operational guidelines such as SAS, IAS, AG, IAG and the likes.

\section{viii) Advertisement for Professional Work}

Accountants are not expected to advertise their services and skill unfairly. No one should give undue prominence to his signboard or advertise in any media unless: recruiting staff for his firm; recruiting staff for his client; acting for client in buying and selling of properties; opening a new office or changing the address of the practice; announcing the appointment of members to important post; and placing congratulatory messages or obituaries in the dailies in respect of members (Atu, n.d.).

\section{ix) Retention of Working Papers}

Working papers should be retained as follows:

- Taxation working papers 7 years;

- Files of chargeable assets 11 years;

- Files of members as trustee 7 years;

- Files for voluntary liquidation 5 years.

\section{(j) Client's Money}

Client's money should be paid in a separate bank account and never to the accountant's personal or firm account.

\section{Concept of Financial Reporting}

Glautier and Underdown (2001) stated that the primary objective of financial reporting is to communicate economic measurement of an information about resources and information about the resources held by entity 
and performance of the reporting entity, which is useful to those having the right to such information. According to Alexander and Britton (2000), the fundamental objective of corporate report is to communicate economic measurements of and information about the resource and performance of the reporting entity, which is useful to those having the rights to such information. Nzotta (2008) stated that financial reports assist the user in evaluating the past and present performance of the organization and its ability to maximize the wealth of the shareholders. Furthermore, it assesses the ability of the firm to create value and objective assessment of the value created over time, financial reports insights into these resources held by an organization, the claims to these resources including the obligation of the firm to transfer resource to other entities and owners, and the effects of transactions, events, and circumstances that changes its resource and claims to these resources (Glauter \& Underdown, 2001; Nzotta 2008).

\section{Theoretical Framework}

Homa (2015) is of the view that there are five ethical theories, namely: Utilitarianism, Egoism, Deontological Ethics, Categorical Imperative, and Virtue Ethics. Utilitarianism focuses on the question of whether the action benefits the people more than it harms them. It takes into consideration the impact by everyone, including the individual. Individuals' self-interests are cast aside. All actions recommended are done to enhance the good of the largest number of people, which is what philosophers termed as "altruism" (Duska, 2011).

Egoism focuses on whether the action is good for us. Concerns of oneself take priority over what might be best for others. It does not consider what is fair to all human beings, but focuses on the belief that people should act in their best interest (Duska, 2011). Deontological Ethics focus on fairness. Fairness takes priority over any consequences the actions would have. The overall key points to this theory are a focus on fairness, rights, commitments, and doing the right thing. People should not only think of their own wants and desires but also that of others (Duska, 2011).

Categorical Imperative goes along with deontological theory, and the focus is on people being treated fairly. There is also a focus on leading by example. If you want others to act ethically, then you must also act ethically. This theory shows that all people are equal and must abide by the same rules (Duska, 2011). Virtue Ethics focus on character traits that are acknowledged across cultures. There is a focus on reaching the end goal or purpose to achieve full potential. Focus is on virtues and moral character and not on duties, rules, or consequences. The emphasis has been taken away from the consequences of the actions, and it focuses on the kind of person who is performing the action (Sadler, 2011). 


\section{Methodology}

The population of the study ideally should comprise of all staff of audit firms in Nigeria. The study, however, focused on accounting staff of the audit firms in the major business centers across Nigeria. Considering the difficulty of observing the entire population, the simple random sampling technique was utilized in selecting a sample size of 75 consisting of accountants and auditors in Lagos, Rivers, Kano, Oyo, Anambra, and Abuja. Regression analysis was used to build the working model, expressing the hypothesized relationship between the independent variables and the dependent variable. In formal terms, the research is quantitatively expressed in the following equations:

$$
\begin{aligned}
& \mathrm{RLB}_{\mathbf{j}}=\beta_{0}+\beta_{1} \mathrm{PRF}+\beta_{2} \mathrm{INV}+\beta_{3} \mathrm{COV} \\
& \mathrm{UNV}_{\mathbf{j}}=\alpha_{0}+\alpha_{1} \mathrm{PRF}+\alpha_{1} \mathrm{INV}+\alpha_{1} \mathrm{COV}
\end{aligned}
$$

Where $\alpha$ and $\beta$ are parameters of the regression equation, PRF and INV are measures of the independent variables (PRF is acronym for professional competence, INV is acronym for independence), UNV and RLB are understandability and reliability respectively which are proxies to the dependent variable, and $\mathrm{COV}$ is the control variable. While $\alpha 0$ and $\beta 0$ can take any value and direction, the same cannot be said for the other coefficients $(\alpha 1$, $\beta 1, \alpha 2$, and $\beta 2$ ). In line with the hypotheses of the study, the a priori expectation for the direction of association was measured by the slopes of the regression lines of equations 1 and 2 as follows:

$$
\alpha_{1}>0, \alpha_{2}>0, \beta_{1}>0 \text {, and } \beta_{2}>0
$$

\section{Data Analysis and Discussion of Findings}

Two copies of questionnaire were distributed to each of the firms in the list. The questionnaire was designed using the five-point Likert scale of strongly agree (5), agree (4), indifference (3), disagree (2), and strongly disagree (1). Section A of the questionnaire was constructed using "leading measures" of measuring organization performance. Leading measures are nonfinancial measures relating to customers perspective, internal business process perspective, and learning and growth perspective. Section B of the questionnaire was designed to include questions that pertain to ethics and organizational performance.

A total of 90 copies were dispatched successfully but only 80 were returned, thereby recording a response rate of 89 percent. Out of the returned 75 filled questionnaires, 5 were discarded because of their failure to meet the necessary conditions for inclusion in the final analysis. The whole of the remaining 75 copies of the questionnaires were used in the statistical analysis. 
Table 1.

\begin{tabular}{|l|l|l|l|l|l|}
\hline $\begin{array}{l}\text { Variables: } \\
\text { Independent }\end{array}$ & $\begin{array}{l}\text { Overall } \\
\text { Score }\end{array}$ & Verdict & $\begin{array}{l}\text { Internal } \\
\text { Consistency } \\
\text { Cronbach } \\
\text { Alpha) }\end{array}$ & EigenValues & $\begin{array}{l}\text { Proportion } \\
\text { Explained }\end{array}$ \\
\hline Professional & 2.5 & Average & 0.8008 & 3.248 & $74.9 \%$ \\
\hline Competence & 2.5 & Average & 0.8431 & 3.248 & $81.2 \%$ \\
\hline Reliability & 2.3 & Very Low & 0.8521 & 3.119 & $78.0 \%$ \\
\hline Understandability & 2.5 & Average & 0.9470 & 3.488 & $69.8 \%$ \\
\hline Ownership Structure & 2.2 & Very weak & 0.8550 & 2.327 & $77.6 \%$ \\
\hline
\end{tabular}

The variables seem to go in the same direction (low), suggesting that all the variables are positively related. The implication of these scores is that accounting ethics among accountants are positively correlated with the financial statement quality produced by them. Thus, results from descriptive statistics show that the overall average financial statement quality for the investigated accountants is 48.90 per cent (or 2.540 on 5-point Likert scale). On the other hand, results from descriptive statistics show that the overall average accounting ethics of accountants is 50.08 per cent (or 2.599 on 5-point Likert scale)

Furthermore, the strength and direction of relationships which were observed, as measured by Pearson's product moment correlation coefficients, reveals bivariate relationship magnitude of between 0.542 (weak relationship) and 0.952 (very strong relationship), both figures expressed in absolute terms.

Table 2. Correlation Matrix

\begin{tabular}{|l|l|l|l|l|l|}
\hline & IND & COM & OWN & REL & UND \\
\hline IND & 1.000 & & & & \\
\hline COM & 0.543 & 1.000 & & & \\
\hline OWN & 0.823 & 0.442 & 1.000 & & \\
\hline REL & 0.952 & 0.552 & 0.857 & 1.000 & \\
\hline UND & 0.857 & 0.676 & 0.720 & 0.856 & 1.000 \\
\hline
\end{tabular}

There are a total of two equations which expresses the hypothetical relationships among the various variables of interest based on the current study. Equation 1, without the $O W N$ term, enables the testing of hypotheses 1 and 2. Similarly, equation 2 facilitates the testing of hypotheses 3 and 4 . Therefore, the tests of hypotheses are carried out in serial sequence of equations beginning from equations 1 through equation 2 without the control variable, and a repeat of test with the inclusion of the control terms.

\section{Equation 1 Results}

Using the OLS technique, we obtained the results as presented in Table 3 below: 
Regression Statistics

Table 3. Summary Output (Equation 1)

\begin{tabular}{|c|c|c|c|c|c|c|}
\hline \multicolumn{2}{|l|}{ Multiple R } & 0.893 & & & & \\
\hline \multicolumn{2}{|l|}{ R Square } & 0.799 & & & & \\
\hline \multicolumn{2}{|c|}{ Adjusted R Square } & 0.793 & & & & \\
\hline \multicolumn{2}{|c|}{ Standard Error } & 1.630 & & & & \\
\hline \multicolumn{2}{|c|}{ Durbin - Watson } & 1.969 & & & & \\
\hline \multicolumn{2}{|c|}{ Observations } & 75 & & & & \\
\hline & $D f$ & $S S$ & $M S$ & $F$ & Significance $F$ & \\
\hline Regression & 2 & 720.556 & 360.228 & 135.631 & 0.0000 & \\
\hline Residual & 72 & 183.260 & 2.656 & & & \\
\hline \multirow[t]{2}{*}{ Total } & 74 & 903.726 & & & & \\
\hline & Coefficients & $S E$ & $t$ Stat & $P$-value & Lower $95 \%$ & Upper $95 \%$ \\
\hline Intercept & -0.1962 & 0.1941 & -1.0108 & 0.3156 & -0.5834 & 0.1910 \\
\hline IND & 0.7463 & 0.0694 & 10.7545 & 0.0000 & 0.6078 & 0.8847 \\
\hline COM & 0.3774 & 0.0813 & 4.6429 & 0.0000 & 0.2153 & 0.5396 \\
\hline
\end{tabular}

With a coefficient of determination (adjusted-R2) of 0.793 , there appears to be a highly dependable relation between $U N D$ and the two proxies of accounting ethics. The standard error of 1.630 indicates that the fitness of the model is good. This is confirmed by the Fstatistic (135.631) and Fsignificance with a near zero value. The model is stable and robust with mild signature of positive autocorrelation as indicated by the Durbin-Watson statistic of 1.969. It implies that about 79 per cent variability of financial statement understandability can be explained by changes in the combined independent variables of professional competency and independence. Both $C O M$ and IND turned out to be positively signed as expected, with $p$-values of 0.0000 . Therefore at $5 \%$ level of significance, the null of zero coefficients for both variables are rejected, thereby confirming their statistical significance.

\section{Regression Statistics}

Table 4. Summary Output (Equation 2)

\begin{tabular}{lccccc}
\hline Multiple $R$ & & 0.953 & & & \\
R Square & & 0.911 & & & \\
Adjusted R Square & & 0.908 & & & \\
Standard Error & & 0.741 & & & \\
Durbin - Watson & & 1.897 & & & \\
Observations & & 75 & & Significance $\boldsymbol{F}$ \\
& $\boldsymbol{d f}$ & $\boldsymbol{S S}$ & $\boldsymbol{M S}$ & $\boldsymbol{F}$ & \\
& & & & & \\
\hline Regression & 2 & 375.982 & 187.991 & 342.827 & 0.000 \\
Residual & 72 & 37.837 & 0.548 & & \\
Total & 74 & 413.819 & & & \\
\end{tabular}




\begin{tabular}{lccccrc} 
& Coefficients & $\boldsymbol{S E}$ & $\boldsymbol{t}$ Stat & P-value & Lower95\% & Upper95\% \\
\hline Intercep & -0.333 & 0.088 & -3.7804 & 0.0003 & -0.5094 & -0.1575 \\
IND & 0.6733 & 0.0315 & 21.3538 & 0.0000 & 0.610 & 0.7362 \\
COM & 0.0422 & 0.0369 & 1.1437 & 0.2567 & -0.0314 & 0.1159 \\
\hline
\end{tabular}

In respect to financial statement reliability, there seems to be a very strong coefficient of determination (adjusted-R2) as indicated by the obtained result (0.908). This means that the relationship between REL and the two proxies of accounting ethics (COM and IND) is very strong, such that besides COM and IND, there are other factors accounting for just about 9.4 per cent of variability of REL. The standard error of 0.741 further confirms the model's goodness-of-fit. The F-statistic (342.827) and F-significance with a near-zero value all bear testament to the overall structural fitness of the model. The model is stable and robust with negligible traces of positive autocorrelation as indicated by the Durbin-Watson statistic of 1.897. Of the two proxies of accounting ethics, only IND turned out to be significant at 5\% level.Interestingly, both COM and IND also turned out to be positively signed as expected.

Inconclusion, therefore, the result obtained leads to the acceptance of $\mathrm{H} 04$ and rejection of $\mathrm{H} 03$.

Table 5. Summary of Hypotheses Decision Table

\begin{tabular}{|l|l|l|}
\hline Hypotheses & Rejected & accepted \\
\hline $\mathrm{H}_{01}$ & YES & NO \\
\hline $\mathrm{H}_{02}$ & YES & NO \\
\hline $\mathrm{H}_{03}$ & YES & NO \\
\hline $\mathrm{H}_{04}$ & NO & YES \\
\hline
\end{tabular}

\section{Conclusion}

The data analyses have produced a number of results. Professional competence is observed to have significant and positive relation with financial statement understandability. This means that the more the reporting accountant is perceived to be professionally competent by financial statement users, the better their understandability of the financial statement. This analysis tends to suggest the notion that financial statement users' perception of the competence level of reporting accountants determines the users' understandability of the financial statement. Membership to professional accounting body should be determined by rigorous assessment of competency test. Furthermore, existing members should be made to undergo mandatory continuous competency training. Since man, by his nature, has a tendency towards aversion to learning, it becomes imperative for members (both existing and intending) to be compelled to learn the requisite skills and 
training. Hence, this gives further fillip to the interventionist argument of regulation theory. The findings also propose that professional competence is insignificantly but positively related with financial statement reliability. The findings suggest that financial statement users' perception of the reporting accountants and auditors' competence does not affect their reliability on the financial statement produced. The findings of this study also stated that the perceived professional independence of the reporting accountant in the industry by financial statement users is positively and significantly associated with their understandability and reliability of the financial statement. Finally, this moderates the relationship between financial statement reliability and accounting ethics, but it fails to moderate the relationship between financial statement understandability and accounting ethics.

In general, these findings which are in agreement with those of Egini and Dike (2014), and Ogbonna and Appah (2011), confirms the ethical theory of relativism which holds that morality is relative to the norms of one's culture. This means that whether an action is right or wrong depends on the moral norms of the society in which it is practiced. The same action may be morally right in one society, but it can be morally wrong in another. For the ethical relativist, there are no universal moral standards that can be universally applied to all people at all times. The only moral standards against which a society's practice can be judged are by its own standards. Thus, professional competence of the reporting accountant is perceived to be insignificant in affecting the reliability of the financial statement. However, his perceived level of independence affects his reliability.

\section{Recommendations}

To ensure that auditors and professional accountants abide by professional ethical standards and guidelines as enshrined and recommended in their professional body codes and other regulatory authorities, the following policy recommendations are prescribed:

1. There should be more rigorous quality control measures by different audit firms, and emphasis should be placed on quality monitoring by the professional accounting bodies in Nigeria.

2. Extended audit tenure should be discouraged by corporate organization and regulatory bodies in Nigeria.

3. Accounting professional bodies should recommend that a harder punishment should be enforced on erring auditors in Nigeria.

4. The composition of the Board of Directors and Audit Committees should be made up of people with corporate experience, proven integrity, and financial expertise for member of audit committees especially the chairman. 
5. Provide Detailed Foundation: The more descriptive and specific ethics-related policies and procedures are, the easier it is to evaluate behavior against ethics code.

6. Develop Metrics: Tangible ethics measures - adding ethics goals to annual performance reviews and, where possible, tying compensation to ethical behavior.

7. Create a Cross-functional Team: Include HR Professional, Ethics and Compliance Manager, Internal Auditor, and Legal Manager.

8. Audit Efficiently: Create a plan and discuss the plan with staff involved in the audit.

9. Look for Other Issues: Risk review: e.g., revenue - recognition, implications, etc.

10. Respond consistently and communicate through the following:

a. Use ethics issues to obtain lessons learned.

b. Discipline ethics violation.

\section{References:}

1. Adetula, D., Okere, W., Ogundana, O. et al. (2017). Auditor's report and investment decisions in Nigeria: The standpoint of accounting academics. J Manag Adm.;1(1):181-95.

2. Arowolo, D. (2012). "Ethics, Motivation and Performance in Nigeria's Public Service" Public Policy and Administration Research Vol.2, No.5.

3. Arowoshegbe, AO., Uniamikogbo, E., \& Atu, G. (2017). Accounting Ethics and Audit Quality in Nigeria. Asian $\mathbf{J}$ Econ, Bus and Acc.;4(2):1-15.

4. Cole, G. (2002). Management theory and practice, Harper and Printers Limited, London.

5. Enderl, G. (2006). Developing Business Ethics in China. New York: Palgrave Macmillan.

6. Fisher, J. (2004). Social responsibility and ethics: clarifying the concepts. Journal of business ethics 52(4), 391-400.

7. Glaucher, M.W.E. \& Underdown, B. (2001). Accounting Theory and Principles.7th Edition Hurlow Prentice Hall and Financial Times, Essex.

8. IFAC (2005). Code of Ethics for Professional Accountants. Available at: www.ifac.org (accessed May.2019). Institute of Chartered Accountants of Nigeria (ICAN) (2009). Professional code of conduct and guide for members.

9. Institute of Internal Auditors- North America (IIANA) (n.d.). (2017). Code of Ethics. https://na.theiia.org/standards-guidance/mandatoryguidance/Pages/Code-ofEthics.accessd 12/9/2019. 
10. International Federation of Accountants Education Committee (2003). International education standards for professional accountants, available at hhttp://www.ifac.org/Members/DownLoads/IES_16.pdf (accessed 12 April 2019).

11. Iyoha, F., Ojeka, S. \& Ogundana, M. (2017). Impact of ethics on the conduct of professional accountants in Nigeria, Proceedings of 2017 3rd International Conference on Creative Education, Kuala Lumpur, Malaysia.

12. Jackling, B., Cooper, B. J., Leung, P. \& Dellaportas, S. (2007). Professional accounting bodies' perceptions of ethical issues, causes of ethical failure and ethics education. Managerial Auditing Journal, 22(9): 928-944. Emerald Group Publishing Limited.

13. Kwame, B. (2014). The 44th Ican Annual Accountants' Conference Sustaining Ethical Standards In The Accountancy Profession Wednesday, September 10, 2014 International Conference Centre Abuja.

14. Miner, K. (2002). Business ethics: a sustainable approach. Business Ethics: A European Review, 11: 137-139.

15. Mintz, S. M. \& Morris, R. E. (2007). Ethical obligations and decision making in accounting: Text and cases. NY: McGraw-Hill Irwin.

16. Ojeka, S., Ogundana, M. \& Iyoha, F. (2017). Impact of ethics on the conduct of professional accountants in Nigeria, Proceedings of 2017 3rd International Conference on Creative Education, Kuala Lumpur, Malaysia, 2017.

17. Ryan, L.V (2004). Toward a corporation with conscience.Strategic Finance, 85, 20-21.

18. Rist, J. M. (2002). Real Ethics, Reconsidering the Foundations of Morality. Cambridge University Press.

19. Scott, A. \& Lyman, R. (1986). The new theory of the firm. American Economic Review, 80, 148-153.

20. Tipgos, M. A. \& Keefe, T. J. (2004).A comprehensive structure of corporate governance in post-Enron corporate America.The CPA Journal, 74, 46-50.

21. Talebinia, G., Salehi M., \& Jabbarzade, S. (2011). A study of the impact of collapse bon financial reporting quality of listed companies. Some Iranian evidence. African Journal of Business Management, 5(10), 3858-3865.

22. Weaver, G., Trevino, K. \& Cochran, P. (1999). Corporate ethics practices in the mid-1990: An empirical study of the fortune 1000. J Bus Ethics.;18(3):283-94. 